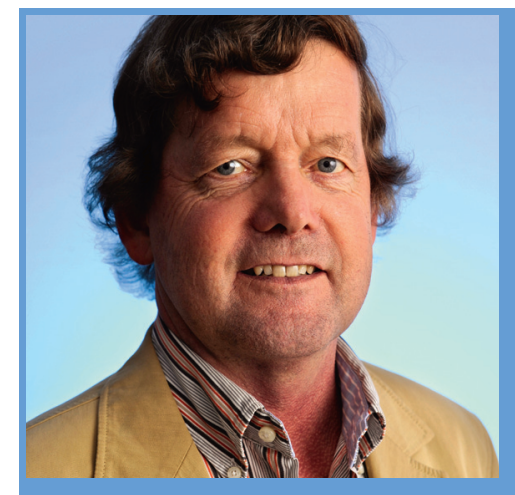

Johan Arends is sinds 1986 neuroloog. In 1984 promoveerde hij aan de Radboud Universiteit in Nijmegen op experimenteel onderzoek in de epilepsie. Vanaf I986 tot I995 had hij een farmacologisch onderzoekslaboratorium bij Janssen Pharmaceutica waar hij betrokken was bij de (klinische) ontwikkeling van stoffen voor behandeling van slaap en epilepsie. In deze periode was hij ook parttime werkzaam in Kempenhaeghe waar hij in I988, samen met Guus Declerck, het slaap-spreekuur startte. Vanaf 1995 is Johan fulltime werkzaam in Kempenhaeghe als hoofd van het slaapcentrum (tot I997) en van de afdeling klinische neurofysiologie (tot 20II). In 20II werd hij parttime hoogleraar aan de Technische Universiteit Eindhoven met als opdracht Ambulatory monitoring of epilepsy and related disorders. Hier vervolgde hij zijn onderzoek naar aanvalsdetectie. Na de oprichting in 20Ir van het landelijke TeleConsortium Epilepsie kreeg dit onderzoek een flinke versnelling, wat geleid heeft tot een nieuw detectie-apparaat, de NightWatch. Daarnaast doet hij onderzoek naar beslisondersteuning en expertsystemen. In december 2018 gaat Johan met pensioen.

Door: Johan Arends (arendsj@kempenhaeghe.nl), neurologie, Academisch centrum voor Epileptologie Kempenhaeghe/ Maastricht UMC+, Heeze/Maastricht en Technische Universiteit Eindhoven en Frans Leijten, neurologie, Hersencentrum Rudolf Magnus en Universitair Medisch Centrum Utrecht.

\title{
Het belang van nachtelijke aanvalsdetectie
}

Het detecteren van epileptische aanvallen is vooral van belang tijdens de nacht. In deze periode is geen goede observatie mogelijk en treden relatief veel aanvallen op. Ook kan plotselinge dood door epilepsie optreden (Sudden Unexpected Death in Epilepsy, SUDEP). Daarom is er behoefte aan een alarmeringssysteem voor nachtelijke epileptische aanvallen. Dat geldt voor de chronische professionele zorg, met personeelstekorten in de nacht, en voor ouders van een kind met nachtelijke aanvallen. Uit EEG-registraties blijkt dat patiënten hun nachtelijke aanvalsfrequentie onderschatten, terwijl verwanten vaak het gevoel hebben dat er een gebrek is aan controle wanneer de persoon met een epileptische aanval hulp nodig heeft.

Veiligheid in de epilepsiezorg verbeteren betekent allereerst het tegengaan van de complicaties van de aanvallen. Dit houdt in dat de riskante aanvallen, vooral 's nachts, moeten worden opgemerkt. Thuis gebeurt dat meestal direct door de ouders of met de babyfoon. Instellingen moeten de zorg op hetzelfde niveau brengen als thuis, waar de middelen veel beperkter zijn. Het is bekend dat 'uitluisteren' het risico op SUDEP met ongeveer een factor drie verlaagt (Harden et al., 20I7) maar dit uitluisteren kent veel valse alarmen. Ook het EEG is minder geschikt als bewaking op langere termijn. Daarom is door het TeleConsortium Aanvalsdetectie Epilepsie ${ }^{\mathrm{I}}$ - een samenwerking tussen academische centra, patiëntenbelangenorganisaties en bedrijven - vol ingezet op de ontwikkeling van adequate detectieapparatuur op basis van eenvoudig te meten veranderingen, zoals veranderingen in hartritme en beweging. Automatische detectie van videobeelden, geluid of spieractiviteit wordt nog nader onderzocht.

\section{De NightWatch}

Het meest in het oog springende resultaat van het TeleConsortium is tot nu toe de ontwikkeling van de NightWatch. De NightWatch is een armband die op basis van een multimodaal algoritme, dat is gebaseerd op verande-

${ }^{1}$ Het TeleConsortium Aanvalsdetectie Epilepsie is een samenwerkingsverband tussen het Academisch Centrum voor Epileptologie, Kempenhaeghe \& MUMC+, Stichting Epilepsie Instellingen Nederland (SEIN), het Universitair Medisch Centrum Utrecht (UMC Utrecht), de Technische Universiteit Eindhoven, Hobo Heeze BV, Pontes Medical, het Epilepsiefonds, LivAssured, CLB Integrated Solutions B.V. en patientenbelangenorganisaties Epilepsie Vereniging Nederland (EVN), Stichting Dravetsyndroom en Stichting Zorg Intensiefen Epilepsie (ZIE). 
ringen in hartslag en beweging, verschillende soorten epileptische aanvallen 's nachts kan detecteren. De NightWatch werd in een prospectief multicenter onderzoek (LICSENSE) gevalideerd, waarin 28 volwassenen met epilepsie en een verstandelijke beperking werden geïncludeerd (Arends et al., 2018). In totaal werden 700 van de ruim 800 potentieel gevaarlijke epileptische aanvallen (tonisch-clonisch, tonisch > 30 seconden, hypermotorisch of clusters van myoclonieën) door de NightWatch gedetecteerd. De mediane sensitiviteit per persoon was hoog $(86 \%)$, maar het alarm ging ook regelmatig onterecht af (positief voorspellende waarde $49 \%$ ). In vergelijking met de Emfit, een veelgebruikt bedmatje dat bewegingen meet, is de sensitiviteit van de NightWatch veel hoger, terwijl het aantal valse alarmen ongeveer gelijk is. In een vervolgonderzoek (PROMISE, met een subsidie van ZonMw, Health Holland en het Epilepsiefonds) zal de NightWatch gebruikt worden om de detectie van nachtelijke epileptische aanvallen bij kinderen te verbeteren (zie de bijdrage van Westrhenen en Thijs aan deze rubriek).

\section{Aanvalsdetectie op afstand}

In deze rubriek wordt in een bijdrage van Geertsema en Kalitzin beschreven dat ook een simpele videocamera aanvallen die potentieel gevaarlijk zijn automatisch kan detecteren. Uit hun onderzoek bleek dat geavanceerde analyse van de videobeelden nachtelijke tonisch-clonische aanvallen kan detecteren, ook in de thuissituatie. Ook automatische detectie van aanvallen met geluid is veelbelovend (Arends et al, 2016). Het bedrijf CLB heeft geluidsherkenningssystemen ontwikkeld voor allerlei nachtelijke gebeurtenissen die in veel zorginstellingen al worden gebruikt, maar er is nog geen gevalideerde module voor geluiden die ontstaan bij epileptische aanvallen. Eerder onderzoek met akoestische bewaking toonde dat de meeste grote motore aanvallen hoorbaar zijn. Toch bleken de geluiden bij ${ }_{2} \%$ van de tonisch-clonische aanvallen erg zwak. Dit kan verklaren waarom ook met goede uitluistersystemen tonisch-clonische aanvallen gemist kunnen worden (van der Lende et al., 2016). De ontwikkeling van video en audio als aanvalsdetectoren is ook een onderdeel van het PROMISE-onderzoek.

\section{Waar gaat het heen?}

Uit de hier beschreven onderzoeken is gebleken dat biomarkers zoals hartritmeveranderingen, beweging en andere autonome signalen nooit specifiek zijn voor een aanval. Het doel 'geen aanval missen' gaat onvermijdelijk gepaard met veel fout-positieve meldingen (Leijten en the Dutch Tele Epilepsy Consortium, 2018). Het lijkt erop dat dit probleem alleen omzeild kan worden door het combineren van biomarkers in zogenaamde multimodale systemen. Hoe meer biomarkers gecombineerd worden, des te inge- wikkelder de ontwikkeling van een algoritme dat bepaalt of er een alarm moet volgen. Een bedrijf dat een systeem op de markt wil brengen, wil een zo simpel mogelijk systeem dat voor iedereen werkt, waaraan geen knoppen zitten die je moet finetunen. In de praktijk betekent dit dat zo'n generiek systeem op zijn best bij $75 \%$ van de patiënten werkt. Om de overige patiënten te bedienen zijn verschillende strategieën denkbaar. Eén ervan is technisch: meer modaliteiten inbouwen en de algoritmes niet vastleggen maar self-learning te maken. Dit laatste vergt een nieuwe generatie computerchips met laag energieverbruik en hoge performance. De andere is praktisch: hopen dat er verschillende systemen komen, zodat de patiënt kan ondervinden wat het beste werkt. Dit laatste is een realistisch scenario: er zijn al verschillende apparaten commercieel beschikbaar en in Kempenhaeghe en SEIN zijn ook al gespecialiseerde poliklinieken waarin samen met de patiënt wordt gekeken naar het beste apparaat. Deze ontwikkeling loopt vooruit op de broodnodige bewijzen uit veldonderzoek van de werkzaamheid van deze apparaten, en op de vergoeding ervan door verzekeraars.

Tenslotte is er een mogelijkheid om op bestaande apparaten zoals smartwatches en mobieltjes een app te plaatsten die met de sensoren van dit apparaat een alarm bij een aanval genereert. Dit lijkt vooralsnog te onbetrouwbaar, maar het biedt wel interessante mogelijkheden voor het vergaren van big data en voor automatische terugkoppeling. Zo kan een mobieltje bij vermoeden van een aanval eerst de patiënt zelf checken door korte vragen op te dringen, om daarna te besluiten of een buitenstaander moet worden gealarmeerd.

\section{Tot slot}

De Nederlandse onderzoeken hebben geleid tot een betere maar nog niet volmaakte detectie. Het motto is dat niet iedere persoon met epilepsie bewaakt hoeft te worden, maar degenen met het grootste veiligheidsrisico wel, en (als het kan) beter dan nu. Vanwege het grote belang staat dit onderwerp op de kennisagenda van de Nederlandse Vereniging voor Neurologie. Hierover is echter nog vrijwel niets opgenomen in de huidige richtlijn Epilepsie. Binnenkort zal een nieuwe module over aanvalsdetectie in deze richtlijn verschijnen. Lees hierover meer in de bijdrage aan deze rubriek van Uiterwijk en Lazeron. De komende tijd zullen er vele ontwikkelingen volgen, want de dynamiek is groot en het ondernemerschap eromheen werkt aanstekelijk, zoals onze ervaring met het bedrijf LivAssured aantoont. Zelden was onderzoek zo leuk: samen met het hele epilepsieveld, praktisch, leerzaam en relevant, leidend tot een prachtig product 's nachts om de bovenarm van de patiënt. 